\title{
Influence of photoperiod and light intensity on egg performance of Japanese quails
}

\author{
Adnan Memon ${ }^{1}$, Nasir Rajput ${ }^{1 *}$, Muhammad Naeem ${ }^{1}$, Sher Ali $^{2}$, \\ Muhammad Haroon Baloch ${ }^{1}$, Asmatullah Kaka ${ }^{1}$ and Arab Khan Lund ${ }^{3}$ \\ 1. Faculty of Animal Husbandry \& Veterinary Science, Sindh Agriculture University Tandojam-Pakistan \\ 2. University of Veterinary \& Animal Sciences, Lahore-Pakistan \\ 3. Shaheed Benazir Bhutto University of Veterinary and Animal Sciences, Sakrand-Pakistan \\ *Corresponding author's email: drnasirrajput@yahoo.com
}

Citation

Adnan Memon, Nasir Rajput, Muhammad Naeem, Sher Ali, Muhammad Haroon Baloch, Asmatullah Kaka and Arab Khan Lund. Influence of photoperiod and light intensity on egg performance of Japanese quails. Pure and Applied Biology. Vol. 7, Issue 4, pp1294-1300. http://dx.doi.org/10.19045/bspab.2018.700150

\begin{tabular}{llll}
\hline \hline Received: 27/05/2018 & Revised: 17/08/2018 & Accepted: 03/09/2018 & Online First: 06/09/2018
\end{tabular}

\section{Abstract}

The study was conducted to observe the influence of photoperiod and light intensity (LI) on egg production of Japanese quails. A total of one hundred $(n=100)$ quails were divided into five groups (A1,A2, B1, B2 and C) according to the regime of light intensity and photoperiod during growing period (GP) and laying period (LP) i.e. $A_{1}$ kept at LI (80 luxes (GP) for 8 hrs. and 240 luxes (LP) for 16 hrs.), $A_{2}$ kept at LI (20 luxes (GP) for 8hrs. and 60 luxes (LP) for 16 hrs.), $B_{1}$ kept at 5 luxes (GP) for 16 hrs and 15 luxes (LP) for 20hrs, $\mathrm{B}_{2}$ kept at 5 luxes for $12 \mathrm{hrs}$. (GP) and 15 luxes for $18 \mathrm{hrs}$ (LP). The group C was considered as control. The Quails of group $\mathrm{B}_{1}$ produced highest egg production $(70.25 \%)$, hen day egg production $(73.62 \%)$ and egg width $(25.12 \mathrm{~mm})$ as compared to other groups. FCR (1.23) and egg weight $(11.20 \mathrm{~g})$ was better in group $\mathrm{B}_{1}$ among all the groups $(\mathrm{p}>0.005)$. Higher egg size was recorded in the group $A_{1}(32.15 \mathrm{~mm})$ and lower in group $C(30.12 \mathrm{~mm})$. The egg weight was highest $(\mathrm{p}>0.05)$ in the group $\mathrm{B}_{1}(11.20 \mathrm{~g})$ and lowest in group $\mathrm{A}_{1}(9.00 \mathrm{~g})$. It was concluded that, better FCR and feed intake was observed at LI (80 luxes (GP) for $8 \mathrm{hrs}$. and 240 luxes (LP) for $16 \mathrm{hrs,} \mathrm{respectively} \mathrm{and} \mathrm{photoperiod} 16$ hrs. at 5 luxes during laying period and $20 \mathrm{hrs}$. at 15 luxes during laying period.

Keywords: Egg Production; Light Intensity; Photoperiod; Quail

\section{Introduction}

Japanese quails are small game birds that are widely used for commercial eggs and meat production [1]. Japanese quails basically belong to family Phasianidae and are considered as migratory birds because they migrate from Asia to Europe and vice versa [2]. They are blessed with many desirable characteristics such as rapid growth rate, early sexual maturity, high egg production rate (300 egg/annum), shorter generation interval (3-4 generations/year), small space requirement (200-250 and $150-200 \mathrm{~cm}^{2}$ in litter and cage system respectively), less feed requirement (20-25 g/adult bird/day), short incubation period (17-18 days), less feed cost and less susceptibility to common chicken diseases [3, 4]. These desirable characteristics are the main reason of their transition to commercial poultry production, rearing the quails in large barns or brooder houses which require intensive management. Quail producers are always in efforts to manipulate and modulate environmental 
factors like temperature, humidity, ventilation, gases, light intensity, light duration and light color etc. Among all, light is assumed to be the most critical factor for quail farming but it has vital impact on production efficiency, egg production and health $[5,6]$. Therefore, artificial illumination (light duration and light intensity) is widely used to increase the reproductive performance of laying hens in modern poultry houses. Similarly, light has great influence on the performance of quails. It has been reported that white light intensity (1 lux or higher) is bright enough to stimulate a light-dark cycle in broiler chickens with higher intensities showing a more noticeable circadian rhythm [7].

Several studies have been carried out to investigate the influence of light on the performance of chickens but still the lack of knowledge in our country regarding the light influence on quail performance [8]. Therefore, the current experiment was designed to investigate the effects of photoperiod and light intensity and their suitable regime (luxes) for the maximum performance of Japanese quail.

\section{Materials and methods}

\section{Housing and Lighting treatments}

A total of one hundred $(n=100)$ Japanese quails were purchased (commercial farm) and brought to the poultry farm, department of Poultry Husbandry, FAH \& Vet. Sciences, SAU Tandojam, Sindh Pakistan. Birds were distributed into five groups according to light intensity and photoperiod regime during growing period (GP) and laying period (LP) as following; $\mathrm{A}_{1}$ kept under the light intensity of 80 luxes for 8 hrs. (GP) and 240 luxes for 16 hrs. (LP), and $A_{2}$ under the light intensity of 20 luxes for 8 hrs. (GP) and 60 luxes for 16 hrs. (LP). However, $\mathrm{B}_{1}$ kept under the photoperiod of 5 luxes for $16 \mathrm{hrs}$. (GP) and 15 luxes for 20 hrs. (LP), and $\mathrm{B}_{2}$ under the photoperiod of 5 luxes for $12 \mathrm{hrs}$. (GP) and 15 luxes for 18 hrs. (LP). Group C was kept as control group where birds were provided 5 luxes for $8 \mathrm{hrs}$. (GP) and 15 luxes for 16 hours (LP).

\section{Data collection and analysis method}

The data was collected for the assessment of egg production (\%), hen day egg production (HDEP \%), egg size (mm), egg weight (g) and feed conversion ratio (FCR) for two month experimental period;

Egg production was calculated by using formula: Egg production $(\%)=$ Total no of eggs produced/Total no of birds reared $\mathrm{x}$ 100 .

Hen day egg production (HDEP \%) was calculated by using formula: $\operatorname{HDEP}(\%)=$ Total no. of eggs produced in a day/ Total number of hens present on that day x 100 .

Egg size, length and width were measured by using Vernier calipers.

Egg weight was evaluated by using electric weight balance.

Feed conversion ratio $(F C R)$ was calculated on the basis of total feed intake by quails and weight gain by using formula: FCR = Total feed intake/Total live body weight.

\section{Statistical analysis}

Collected data was statistically analyzed through factorial designed in the tuky $\mathrm{T}$ paired test, using JMP 9.0.1 software of USA.

\section{Results and discussion}

\section{Egg production (\%)}

The egg production (\%) of Japanese quail were assessed and findings are presented in the (Figure 1). The experimental findings showed the maximum egg production of Japanese quail in the group $\mathrm{B}_{1}$ followed by $\mathrm{B}_{2}, \mathrm{C}, \mathrm{A}_{1}$ and $\mathrm{A}_{2}(70.25,69.23,53.84 \%$, 50.11and 48.81 respectively). Analysis of variance showed that the influence was significant $(p>0.05)$ in $B_{1}$ and $B_{2}$ but nonsignificant $(p>0.05)$ in remaining groups. Similar kinds of results have also been reported by Mahmud et al. [9] when they worked on application of different light regimes to improve the performances by 
decreasing physical activity and saving energy expenditure in chicken.

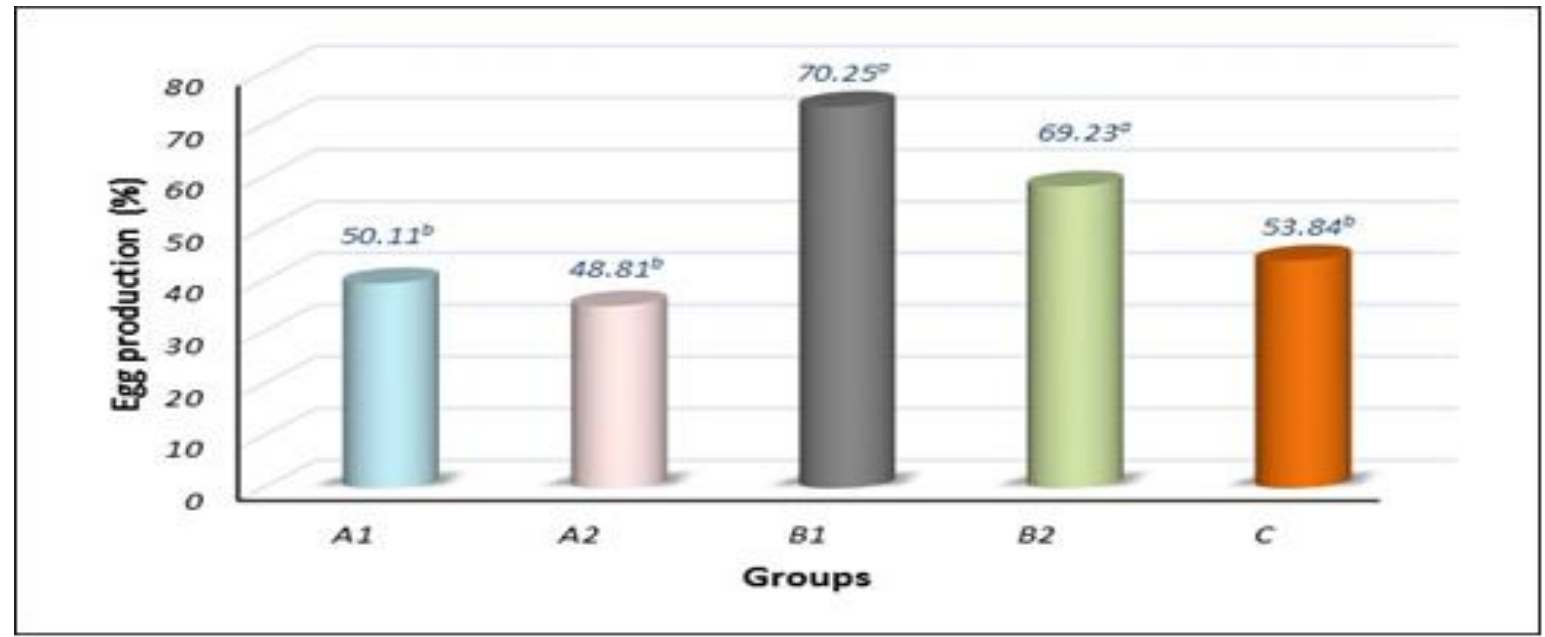

Figure 1. Average egg production (\%) of Japanese quails at various photoperiods and light intensity

\section{Hen day egg production (\%)}

Results regarding hen day egg production $(\%)$ are shown in the (Figure 2). According to findings, the quails of group $\mathrm{B}_{1}$ showed maximum day egg production followed by $\mathrm{B}_{2}, \mathrm{C}, \mathrm{A}_{1}$ and $\mathrm{A}_{2}(73.62,58.24,43.95,39.56$ and 35.16 respectively). But, the difference was non-significant ( $\mathrm{p}>0.05)$ among all groups. These findings are supported by the result of Boon et al. [10] who examined the influence of five different lighting regimes and found that less exposure of photoperiod is more influential in female quails.

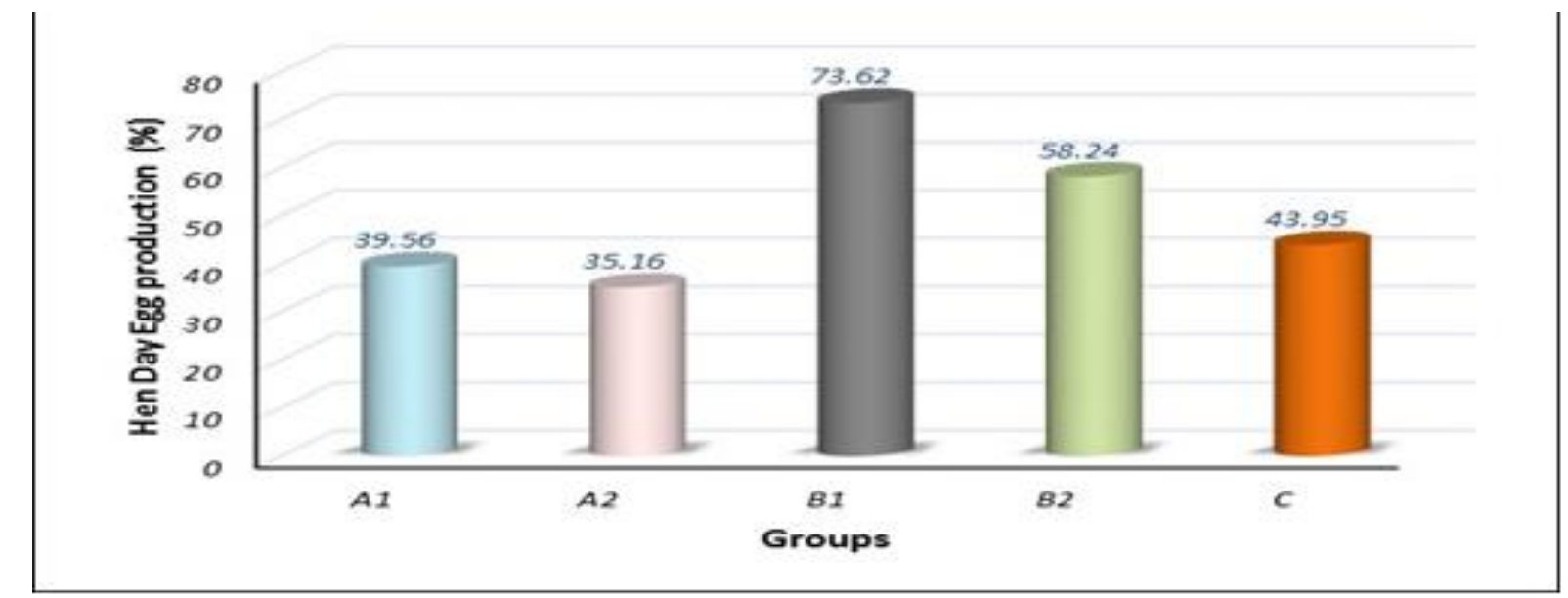

Figure 2. Average egg production (\%) of Japanese quail at various photoperiods and light intensity 


\section{Egg length (mm)}

The egg length of Japanese quail showed the little variation under different light and photoperiod regime and results are illustrated in (Figure 3). It was observed that the quail of $A_{1}$ furnished maximum egg production followed by $\mathrm{A}_{2}, \mathrm{~B}_{1}, \mathrm{~B}_{2}$ and $\mathrm{C}$ $(32.15 \pm 0.54, \quad 32.12 \pm 0.35, \quad 30.25 \pm 0.51$, $30.12 \pm 0.35$ and $30.12 \pm 0.31 \mathrm{~mm}$, respectively). Statistically, it was significant $(p<0.05)$ influence on the birds of group $A_{1}$ and $A_{2}$ while influence was not significant ( $>0.05$ ) among remaining groups. Renema et al. [11] also studied to investigate the influence of light duration on egg production and lying sequence length. Their results are in agreement with the findings of present experiment.

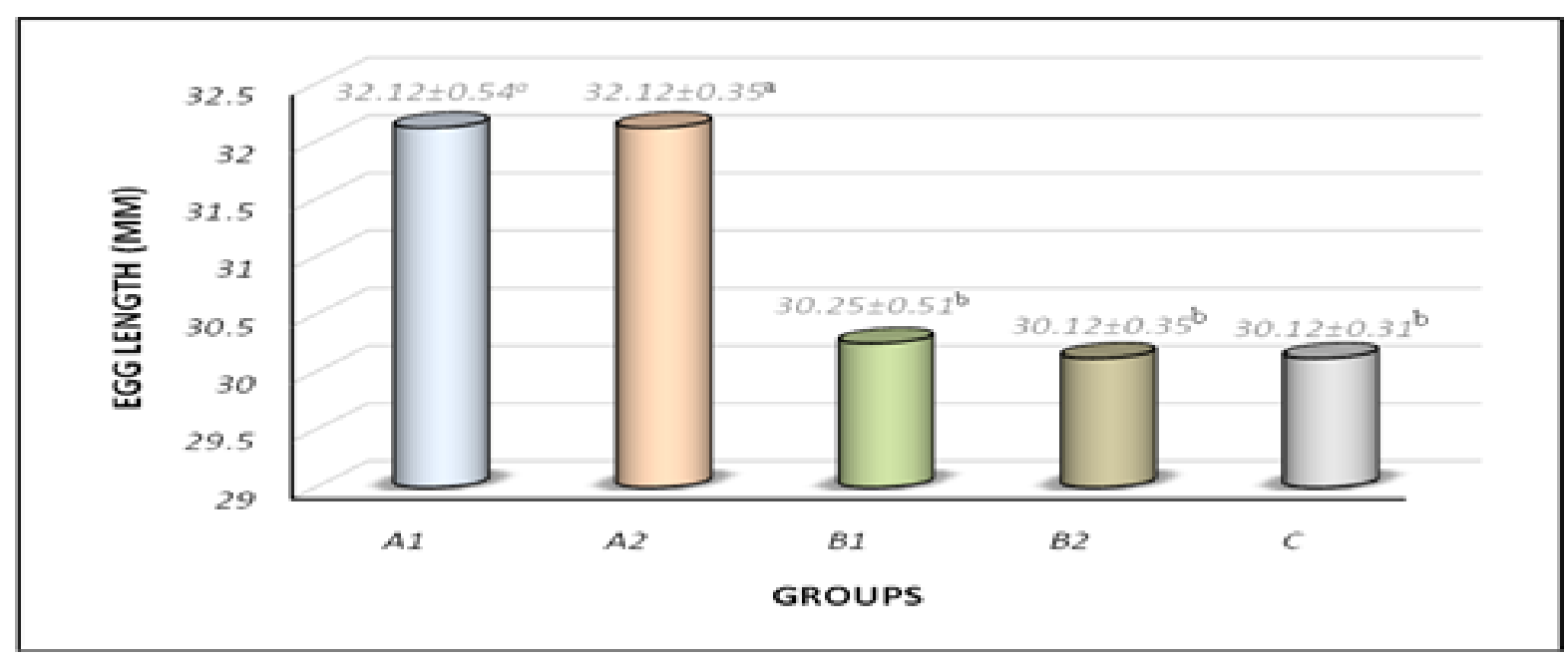

LSD @ $0.05=0.0006$

P-value $=2.8950$

Figure 3. Average egg length ( $\mathrm{mm}$ ) of Japanese quail at various photoperiods and light intensity

\section{Egg width (mm)}

The width of quail eggs were measured and results are given in (Figure 4). The maximum egg width was observed in the group $\mathrm{B}_{1}$ followed by $\mathrm{A}_{1}, \mathrm{~B}_{2}$ and $\mathrm{C}$ $(25.12 \pm 0.44, \quad 24.87 \pm 0.22, \quad 24.37 \pm 0.26$, $24 \pm 0.26$ and $23.75 \pm 0.31 \mathrm{~mm}$, respectively). Statistically, the photoperiod has significant $(p<0.05)$ impact on the egg width of group $\mathrm{B}_{1}$ while non-significant $(\mathrm{p}>0.05)$ influence of photoperiod as well as light intensity were observed in the remaining groups. Visser, [10] reported that the light intensity and its duration had effect on the growth performance of Japanese quails.

\section{Egg weight (g)}

The eggs of quail were weighed and results are presented in the (Figure 5). The maximum egg weight of birds were measured in the group $\mathrm{B}_{1}$ followed by $\mathrm{B}_{2}, \mathrm{C}$, $\mathrm{A}_{2}$ and $\mathrm{A}_{1} \quad(11.20 \pm 0.73, \quad 10.00 \pm 0.31$, $9.20 \pm 0.48,9.00 \pm 0.44$ and $9.00 \pm 0.54 \mathrm{~g}$, respectively). However, the variation was non-significant ( $>0.05)$ among all groups. Wagan et al. [12] reported that the light intensity and photoperiod had not influenced significantly the egg weight of quails. 


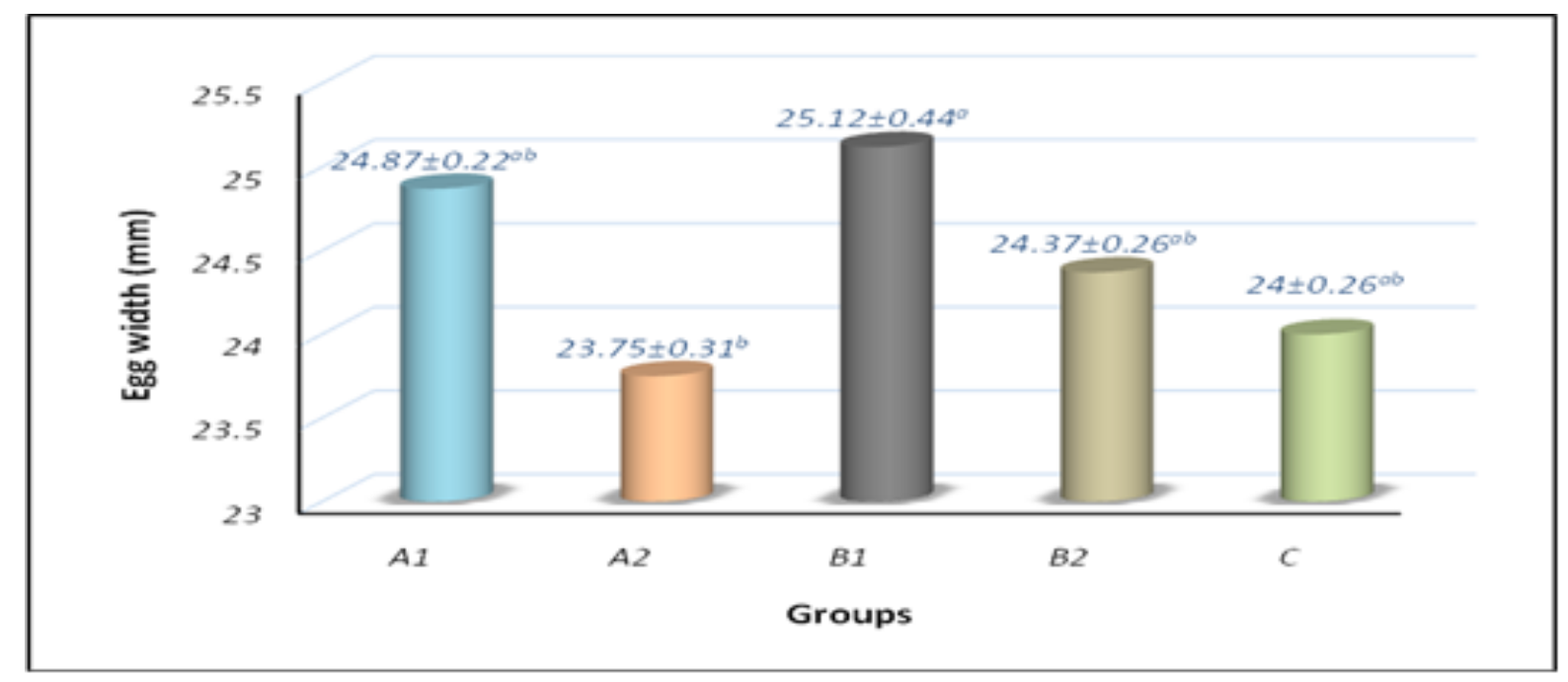

LSD @ $0.05=2.8950, \mathrm{P}$-value = 0.0180

abc with different superscript in column showed significant $(\mathrm{P}<0.05)$ difference

Figure 4. Average egg width $(\mathrm{mm})$ of Japanese quail at various photoperiods and light intensity

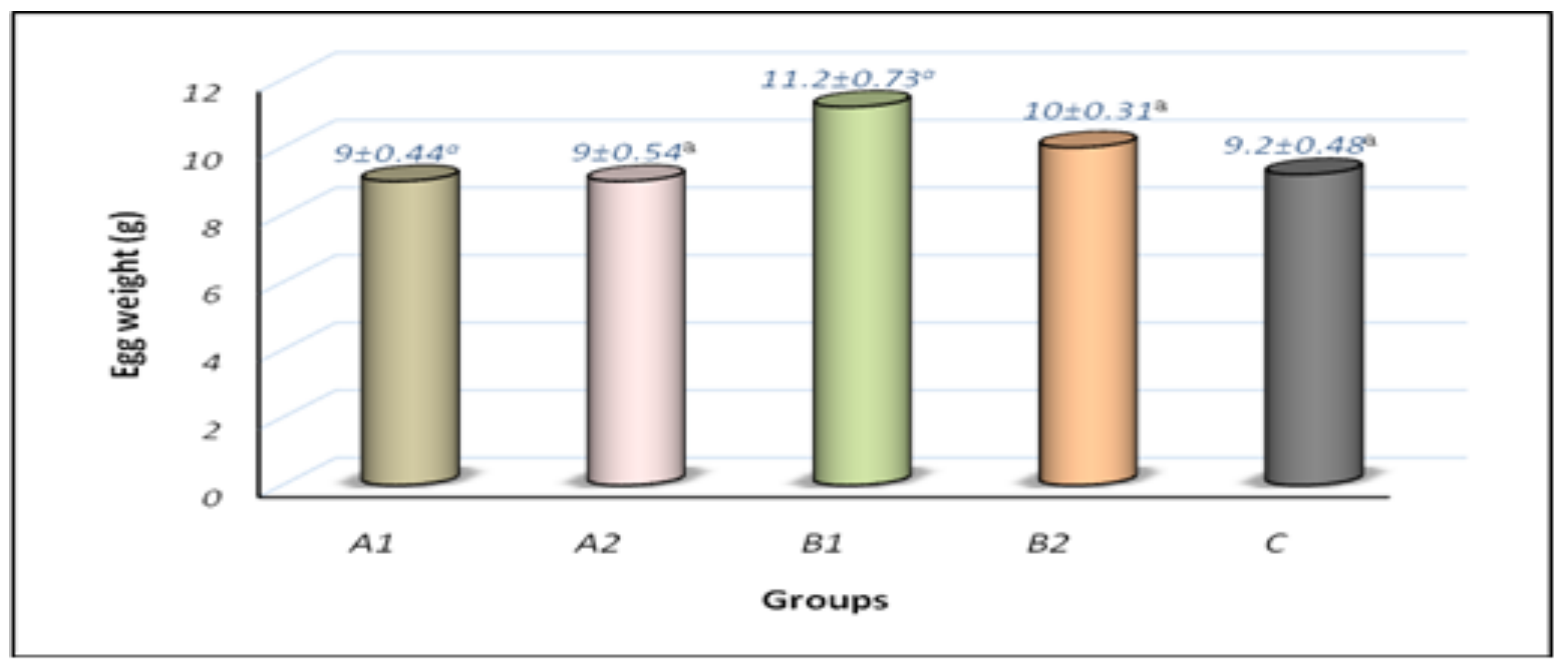

LSD @ $0.05=2.9923$

P-value $=0.0337$

${ }^{a b c}$ with different superscript in column showed significant $(\mathrm{P}<0.05)$ difference

Figure 5. Average egg weight (g) of Japanese quail at various photoperiods and light intensity

\section{Feed conversion ratio}

The feed conversion ratio of quails was evaluated and findings are presented in the (Figure 6). The experiment shows that the FCR was better in group $A_{1}$ followed by group $\mathrm{C}, \mathrm{A}_{2}, \mathrm{~B}_{2}$ and $\mathrm{B}_{1}(1.03,1.08,1.09$,
1.11 and 1.23, respectively). However, the variation was not significant $(\mathrm{p}>0.05)$ among all groups. These findings supported by the results reported by Brickett et al. [13]. 


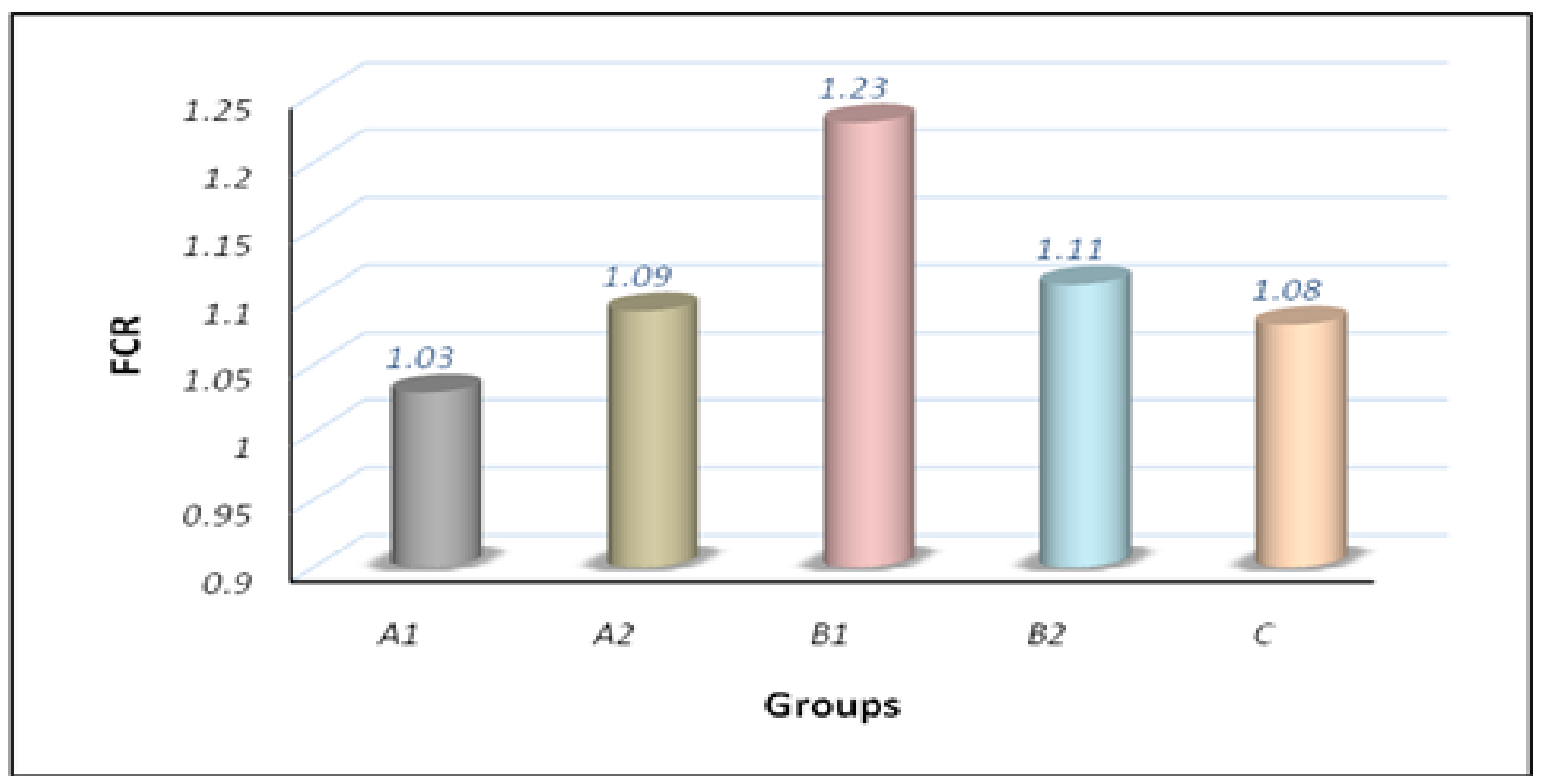

Figure 6. Average FCR of Japanese quail at various photoperiods and light intensity

\section{Conclusion}

Present experimental findings lead to the conclusion that Japanese quails showed better feed conversion ratio and feed intake under the light intensity regime of 80 luxes for $8 \mathrm{hrs}$ during growing period and 240 luxes for 16 hrs during laying period. However, the egg production was improved under the photoperiod regime of 5 luxes for 16 hrs during growing period and 15 luxes for $20 \mathrm{hrs}$ during laying period.

\section{Authors' contributions}

Conceived and designed the experiments: A Memon, N Rajput, M Naeem, S Ali, MH Baloch \& AK Lund, Performed the experiments: A Memon, Analyzed the data: S Ali, MH Baloch \& A Kaka, Contributed materials/ analysis/ tools: N Rajput, Wrote the paper: N Rajput, M Naeem, A Kaka \& MH Baloch.

\section{References}

1. Onyewuchi UU, Offor IR \& Okoli CF (2013). Profitability of quail bird and egg production in imo state. Nig J Agri Food Environ 9(1): 40-44.
2. Saidu S, Afanasyev G, Popova L, Komarchev A \& Ibrahim U (2014). Dynamic of reproductive qualities of Japanese quails. Inter Conf on Earth, Environ and life Sci 23-24.

3. Faitarone ABG, Pavan AC, Mori C, Batista LS., Oliveira RP \& Garcia EA (2005). Report Economic traits and performance of Italian quails reared at different cage stocking densities. Brazil J Poul Sci 7(1): 19-22.

4. Jatoi AS, Khan MK, Sahota AW, Akram M, Javed K, Jaspal MH \& Khan SH (2013). Post-peak egg production in local and imported strains of Japanese quails (Coturnix coturnix Japonica) as influenced by continuous and intermittent light regimens during early growing period. J Anim \& Poul Sci 23(3): 727-730.

5. Olanrewaju HA, Thaxton JP, Dozier WA, Purswell J, Roush WB \& Branton SL (2006). A review of lighting programs for broiler production. Intl $J$ Poul Sci 5(4): 301-308. 
6. Mehmet M, Karabayir A, Ersoy IE \& Cengiz A (2005). Effect of three different lighting programme on live wieght changes of bronze turkey under semi intensive condition. Arch Vet Sci 48(1): 86-90.

7. Blatchford RA, Archer GS \& Mench JA (2012). Contrast in light intensity, rather than day length, influences the behavior and health of broiler chickens. J Poul Sci 91(8): 1768-1774.

8. Kuhles A \& Petersen J (2005). Einfluss von Licht und Dunkelheit auf den Adaptationsprozess beim Hühnerküken-Literaturübersicht. Arch. Geflügelk, 69: 2-10.

9. Mahmud A, Khan MZU \& Javed MA (2011). Effect of different storage periods and temperatures on the hatchability of broiler breeder eggs. $\mathrm{Pak}$ Vet J 31(1): 78-80.

10. Boon P, Visser GH \& Daan S (2000). Effect of photoperiod on body weight gain, and daily energy intake and energy expenditure in Japanese quail (Coturnix C. Japonica). Physiol Behav 70(3-4): 249-260.

11. Renema RA, Robinson FE, Oosterhoff HH, Feddes JJR \& Wilson JL (2001). Effects of photostimulatory light intensity onovarian morphology and carcass traits at sexual maturity in modern and antique egg-type hens. Poultry Sci 80(1): 47-56.

12. Wagan Shakeel Ahmed, Vistro Waseen Ali, Rajput Nasir, Syed Khurram fareed, Nooreen Mehmood, Muhammad Farooq, \& Mashhood Ahmed (2017). Effect of light duration on productivity of Japanese quail. Inter J of Current Res 9(1): 35-37.

13. Brickett KE, Dahiya JP, Classen HL \& Gomis S (2007). Influence of dietary nutrient density, feed form, and lighting on growth and meat yield of broiler chickens. Poult Sci 86(10): 2172-2181. 